\title{
Chemical injury treated with autologous limbal epithelial stem cell transplantation and subconjunctival bevacizumab
}

This article was published in the following Dove Press journal:

Clinical Ophthalmology

30 August 2014

Number of times this article has been viewed

\author{
Gian Maria Cavallini' \\ Graziella Pellegrini \\ Veronica Volante' \\ Pietro Ducange' \\ Michele De Maria' \\ Giulio Torlai' \\ Caterina Benatti' \\ Matteo Forlini' \\ 'Institute of Ophthalmology, ${ }^{2}$ Centre \\ for Regenerative Medicine "Stefano \\ Ferrari”, University of Modena e \\ Reggio Emilia, Modena, Italy
}

Background: Limbal stem cell (LSC) deficiency leads to corneal opacity due to a conjunctivalization of the corneal surface. LSC transplantation, which can be followed by corneal keratoplasty, is an effective procedure to restore corneal transparency; however, a common cause of failure of this procedure is neovascularization (NV).

Methods: A 59-year-old man with a 21-year history of a corneal chemical burn caused by phosphoric acid in his left eye was examined. He presented with unilateral total LSC deficiency with severe conjunctivalization and a corrected distance visual acuity that was limited to hand motion.

Results: We reported the short-term in vivo efficacy of subconjunctival bevacizumab for progressive corneal NV in a patient with LSC deficiency that underwent LSC transplantation. Four months after autologous LSC transplantation and 1 month after the second subconjunctival bevacizumab injection, the patient's corrected distance visual acuity was $1 / 10$.

Conclusion: Subconjunctival injection of bevacizumab can reduce the corneal NV, reducing conjunctival inflammation and supporting restoration of a stable ocular surface that is able to counteract graft failure, with no toxicity for the transplanted LSC.

Keywords: stem cells, bevacizumab, limbal stem cell deficiency, transplantation

\section{Introduction}

The human cornea is known to be an avascular and transparent tissue. Its avascularity is maintained by both an appropriate balance between antiangiogenic and antilymphangiogenic factors, as well as by the integrity of limbal stem cell (LSC) barriers. ${ }^{1,2}$ A wide variety of insults, such as infections, inflammation, ischemia, degeneration, and trauma, can disrupt this balance, leading to corneal neovascularization (NV). ${ }^{1}$

Corneal NV results in a loss of transparency and the consequent loss of visual acuity, lipid deposition, tissue scarring, edema, and a loss of immune privilege, with the progressive worsening of a patient's prognosis. ${ }^{3}$ Several studies have shown that a key role in NV is played by the vascular endothelial growth factor (VEGF) family. In fact, increased levels of corneal VEGF and VEGF receptors have been demonstrated in vascularized cornea. ${ }^{4}$

Bevacizumab is a humanized monoclonal antibody targeting the VEGF, and which has been approved as a first-line therapy for widespread metastatic colorectal cancer. Numerous trials have been published on the off-label intravitreal injection of bevacizumab in ophthalmology, especially for the treatment of neovascular age-related macular degeneration, proliferative diabetic retinopathy, macular edema from central retinal vein occlusion, and refractory pseudophakic cystoid macular edema. ${ }^{5}$
Correspondence: Gian Maria Cavallini Struttura Complessa di Oftalmologia, Azienda Ospedaliero-Universitaria di Modena Policlinico, Via del Pozzo 7I, 41100 , Modena, Italy

Tel +39059360309

Fax +39059371532

Email cavallini.gianmaria@unimore.it 
Recently, bevacizumab has been used for the treatment of anterior segment $\mathrm{NV}$ with promising results in the regression of iris NV, neovascular glaucoma, and corneal NV. Moreover, subconjunctival injections and topical applications of this molecule have shown no toxicity for corneal tissue. ${ }^{6}$

In the event of corneal opacity, allogenic corneal transplantation (keratoplasty) can be performed in order to restore corneal transparency. However, in the event of LSC deficiency, keratoplasty is only temporarily effective; a common occurrence with the procedure is corneal conjunctivalization, which means that there is an invasion of the corneal surface by conjunctival cells with the formation of a conjunctival pannus. ${ }^{7}$ As is known, corneal epithelial renewal is accomplished by the proliferative activity of stem cells located in the limbus, which is a narrow zone that lies between the cornea and the bulbar conjunctiva. ${ }^{8}$ LSC transplantation can restore corneal regenerative function, preparing the corneal surface for keratoplasty. However, despite an immediately satisfying result, corneal NV can occur.

To our knowledge, no studies have been published regarding the possible use of bevacizumab in the event of corneal NV secondary to LSC transplantation. We report the shortterm in vivo efficacy of subconjunctival bevacizumab for the treatment of recurring corneal NV in a patient with LSC deficiency (LSCD) who underwent LSC transplantation.

\section{Methods}

A 59-year-old man with a 21-year history of chemical burn of the cornea caused by phosphoric acid in his left eye presented to our hospital with unilateral total LSCD, severe corneal conjunctivalization, cataract, and a corrected distance visual acuity (CDVA) limited to hand motion in the affected eye.

The patient underwent a $2 \times 2 \mathrm{~mm}$ biopsy of the limbus from the fellow eye; the biopsy material was cultivated on fibrin, a natural substrate that preserves holoclone-forming cells (Centre for Regenerative Medicine, Department of Biomedical Science, University of Modena and Reggio
Emilia, Rome, Italy). Cultured autologous LSC transplantation was performed.

The fibrin-cultured epithelial sheet has been grafted over the corneal and limbal region of the injured eye, where the receiving bed had been previously surgically prepared. A $360^{\circ}$ peritomy was performed and the fibrovascular pannus was carefully removed. ${ }^{9,10}$ The fibrin-cultured epithelial sheet was placed on the prepared corneal wound bed, spanning the limbus about 2-3 $\mathrm{mm}$ to reduce competition with conjunctival in-growth. The conjunctiva was then sutured over the peripheral fibrin sheet with an 8.0 vicryl suture in order to protect the border of the sheet and to help it adhere on the corneal surface (Figure 1). ${ }^{7}$

\section{Results}

The preoperative CDVA was limited to hand motion. Three days before the autologous LSC transplantation, the patient's CDVA was $1 / 100$. The corneal surface was regular and transparent; there was peripheral edema in the nasal sector, and a stromal opacity was evident in the superonasal sector.

Renewal of the corneal epithelium appeared within the first week after transplantation. Two weeks after surgery, the patient's best corrected visual acuity was $2 / 50$. After 30 days from transplantation, we observed almost complete corneal epithelium renewal, a regression of peripheral edema, and progressive corneal NV from the conjunctival tissue at the 12 o'clock and 6 o'clock positions. To reduce the incoming limbal NV, two subconjunctival bevacizumab injections were performed 2 months and 3 months after transplantation.

Commercially available bevacizumab (Avastin ${ }^{\circledR}$; Hoffman-La Roche Ltd., Basel, Switzerland) was injected at a dose of $2.5 \mathrm{mg}(0.1 \mathrm{~mL})$. The injections were administered in the subconjunctival space close to the corneal limbus and adjacent to the area containing the pathological vessels. ${ }^{6}$

Four months after the autologous LSC transplantation and 1 month after the second subconjunctival bevacizumab

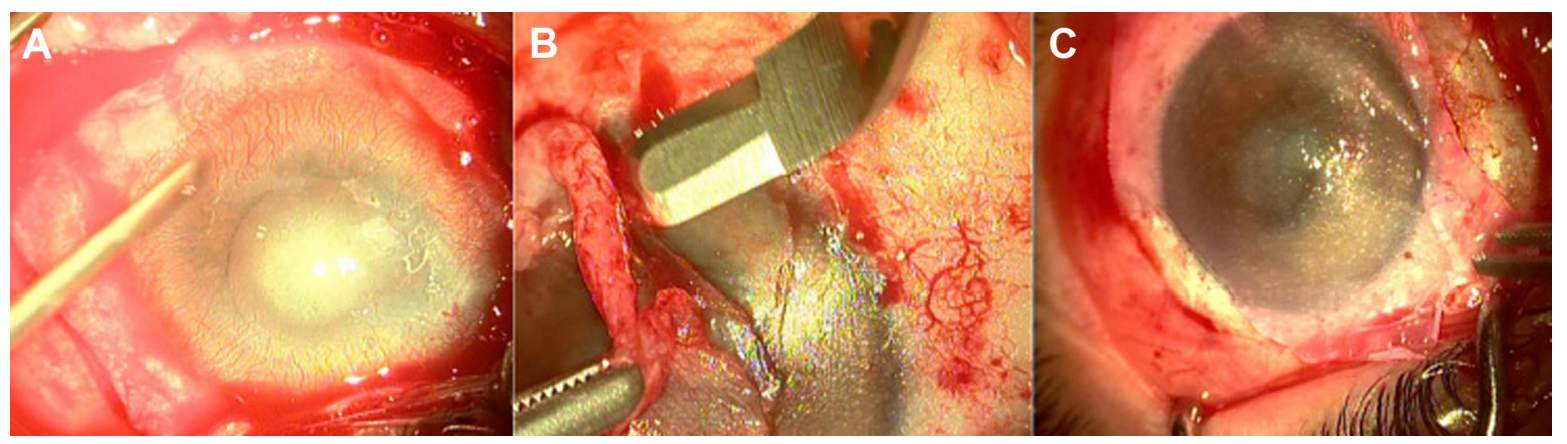

Figure I Surgical procedure.

Notes: (A) Corneal chemical burn by phosphoric acid; (B) surgical removal of neovascular pannus; and (C) fibrin-cultured epithelial sheet positioned on the corneal surface. 


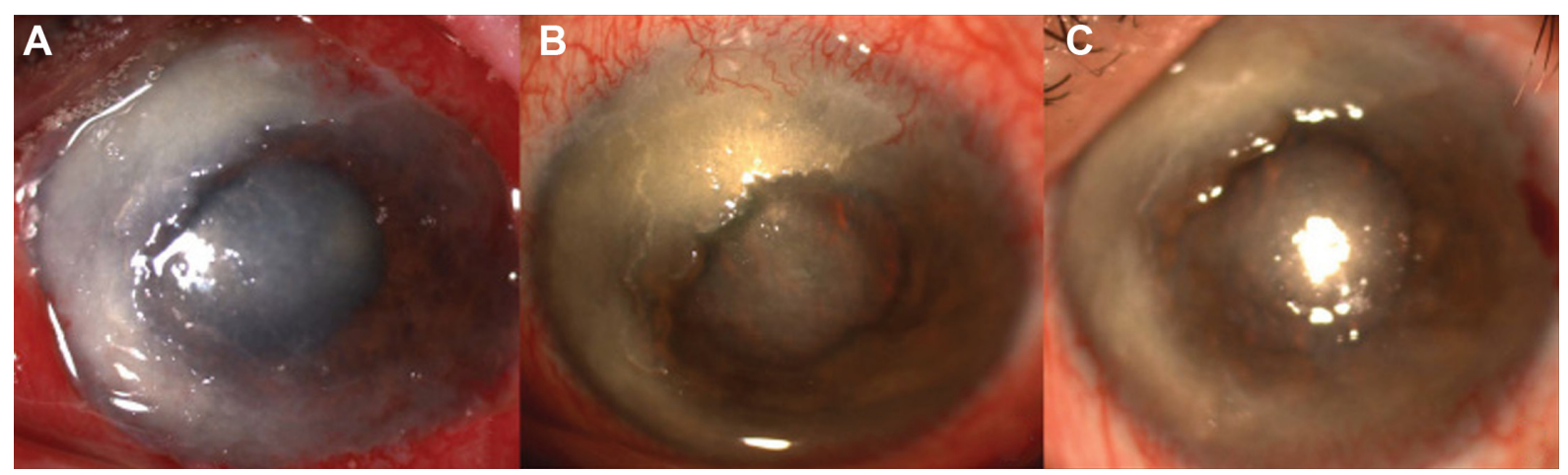

Figure 2 Corneal neovascularization.

Notes: (A) One day after autologous limbal stem cell transplantation; (B) limbal neovascularization 30 days after transplantation; and (C) corneal surface and regression of neovascularization I month after the second subconjunctival bevacizumab injection.

injection was performed, the patient's CDVA was $1 / 10$. Subconjunctival bevacizumab successfully decreased corneal $\mathrm{NV}$ and at 1 month after the second injection, the corneal surface appeared to be regular, transparent, and with no evidence of limbal NV (Figure 2).

\section{Discussion}

Autologous LSC transplantation is an effective technique for the treatment of corneal chemical burns resulting in a LSCD. ${ }^{7}$ In this case report, we used a technique described in literature guidelines..$^{7-9}$ The aim of this study was to report the (off-label) subconjunctival injection of bevacizumab to avoid corneal NV, which can cause autologous LSC transplantation to fail. Our patient underwent two injections of subconjunctival bevacizumab that were administered 1 month apart from each other, resulting in progressive corneal NV slowdown (Figure 2), and a decrease in conjunctival inflammation.

Limbal epithelial stem cell transplantations can be successful in patients with LSCD for the reconstruction of the ocular surface, and they can restore the patient's clinical condition so it can allow for a corneal graft with reduced risk of rejection. Subconjunctival injection of bevacizumab is an easy procedure that successfully reduces corneal NV and conjunctival inflammation, restoring a stable ocular surface that is able to counteract graft failure with no toxicity for the transplanted LSCs.

\section{Disclosure}

The authors report no conflicts of interest in this work.

\section{References}

1. Chang JH, Gabison EE, Kato T, Azar DT. Corneal neovascularization. Curr Opin Ophthalmol. 2001;12(4):242-249.

2. Ellenberg D, Azar DT, Hallak JA, et al. Novel aspects of corneal angiogenic and lymphangiogenic privilege. Prog Retin Eye Res. 2010; 29(3):208-248.

3. Papathanassiou M, Theodoropoulou S, Analitis A, Tzonou A, Theodossiadis PG. Vascular endothelial growth factor inhibitors for treatment of corneal neovascularization: a meta-analysis. Cornea. 2013;32(4):435-444.

4. Epstein RJ, Stulting RD, Hendricks RL, Harris DM. Corneal neovascularization. Pathogenesis and inhibition. Cornea. 1987;6(4):250-257.

5. Yoeruek E, Spitzer MS, Tatar O, Aisenbrey S, Bartz-Schmidt KU, Szurman P. Safety profile of bevacizumab on cultured human corneal cells. Cornea. 2007;26(8):977-982.

6. Benayoun Y, Adenis JP, Casse G, Forte R, Robert PY. Effects of subconjunctival bevacizumab on corneal neovascularization: results of a prospective study. Cornea. 2012;31(8):937-944.

7. Rama P, Matuska S, Paganoni G, Spinelli A, De Luca M, Pellegrini G. Limbal stem-cell therapy and long-term corneal regeneration. $N$ Engl J Med. 2010;363(2):147-155.

8. Pellegrini G, Rama P, Mavilio F, De Luca M. Epithelial stem cells in corneal regeneration and epidermal gene therapy.J Pathol. 2009;217(2): 217-228.

9. Pellegrini G, Rama P, De Luca M. Vision from the right stem. Trends Mol Med. Epub 2010 Nov 11

10. Rama P, Bonini S, Lambiase A, et al. Autologous fibrin-cultured limbal stem cells permanently restore the corneal surface of patients with total limbal stem cell deficiency. Transplantation. 2001;72(9):1478-1485.
Clinical Ophthalmology

\section{Publish your work in this journal}

Clinical Ophthalmology is an international, peer-reviewed journal covering all subspecialties within ophthalmology. Key topics include: Optometry; Visual science; Pharmacology and drug therapy in eye diseases; Basic Sciences; Primary and Secondary eye care; Patient Safety and Quality of Care Improvements. This journal is indexed on

\section{Dovepress}

PubMed Central and CAS, and is the official journal of The Society of Clinical Ophthalmology (SCO). The manuscript management system is completely online and includes a very quick and fair peer-review system, which is all easy to use. Visit http://www.dovepress.com/ testimonials.php to read real quotes from published authors. 